\title{
ENSAYO SOBRE FEMINISMOS, TEORÍA DE GÉNERO Y FEMINICIDIO
}

\section{ESSAY ON FEMINISMS, THEORY OF GENDER AND FEMINICIDE}

Débora Zambrano Gonzales

\section{Resumen}

El ensayo es una invitación a reflexionar sobre la historia y los avances del feminismo o de los feminismos en la época actual. Buscar la conexión entre diversos temas que han surgido de su propio desarrollo. Las teorias sobre el género son parte de la evolución de estos feminismos. Pero la coyuntura actual demanda respuestas más efectivas para detener la violencia contra las mujeres y el feminicidio. Apuntando a retomar la unidad hacia fuera del movimiento feminista y dejar hacia dentro los debates pendientes, que son necesarios, pero que no pueden ser más importantes que la defensa de la vida de las mujeres que más lo necesitan.

Palabras clave: Feminismo; género; Feminicidio; violencia contra la mujer.

\section{Abstract}

This article is an invitation to reflect on the history and progress of feminism or feminisms in the current era. To seek the connection between various issues that have arisen from their own development. Theories about gender are part of the evolution of these feminisms, but the current situation demands more effective responses to stop violence against women and femicide. It also aims to take the unit back from the feminist movement and leave the pending debates in, which are necessary, but which can not be more important than defending the lives of women who need it most.

Key words: Feminism; gender; femicide; violence against women. 


\section{INTRODUCCIÓN}

La reflexión teórica en torno a la mujer en los últimos tiempos en apariencia parece haber disminuido. Mientras, las víctimas de feminicidio y de violencia suman cada día mayores cifras, en el Perú como en otras latitudes del mundo. Se difunde la sensación de que no bastan las leyes que penalicen y castiguen los crimenes de esta naturaleza, para detener este problema. Dice la española Cobo (2012), recuperando a Immanuel Kant en su libro "Filosofia de la Historia", que cuando los grupos sometidos a subordinación cuestionan las reglas del consenso, el Estado y la sociedad sacan de sus profundidades, el principio de excepción que es la violencia, para volver al estado de cosas anteriores. Es obvio dice ella, que Kant no señaló esto pensando en las mujeres, pero que es válido para el ejemplo, considerando que el carácter de la violencia contra la mujer, es histórico. $\mathrm{Y}$ añade, que la muerte de las mujeres hoy expresa un cuestionamiento a ese carácter histórico, enfatizando que existe un imaginario colectivo y profundamente arraigado, en el que las mujeres siguen siendo consideradas todavia como seres inferiores, aun cuando estos vínculos jerárquicos se estén debilitando.

Esta realidad preocupante no niega el hecho de que se han producido avances positivos en la vida de las mujeres, durante el siglo XX y el actual, en materia de independencia y autonomía, aunque lamentablemente todavía atañe a un reducido número de ellas. El matrimonio en occidente es hoy una posibilidad y no un camino obligatorio, la existencia del divorcio le pone fin a relaciones de sometimiento y subordinación eternas y muy por el contrario fomenta matrimonios donde el respeto es una condición necesaria para que sobreviva; el uso de anticonceptivos y la posibilidad de decidir cuantos hijos tener y cuando tenerlos o simplemente no tener hijos, determina el control del cuerpo de las mujeres por ellas mismas. Las mujeres avanzan y a su paso están cuestionando en la práctica viejos moldes de familia y de ser mujer. Todo ello les permite vivir la vida que quieren. Sin embargo, no todo es tan perfecto, porque las libertades conquistadas no la libran de la doble jornada de trabajo, el remunerativo y el no remunerativo.

\section{FEMINISMOS: LOS PRIMEROS PA- sos}

Señala Bernárdez (2015), Directora del Instituto de Investigaciones Feministas de la Universidad Complutense de Madrid (UCM), que la palabra francesa "fèminisme" tiene su punto de partida en 1837, para hablar de la doctrina que exigía los derechos civiles y políticos de las mujeres, dando origen a la reivindicación de su papel en la sociedad, en busca de lograr una igualdad con los varones ante las leyes.

Pero existen múltiples evidencias de que el feminismo llegó en los albores de la ilustración y antes, que se 
expresa por ejemplo en el libro de Pizan (2001) "La ciudad de las damas" escrito en Francia, en1405. La autora cuestiona la situación de subordinación de las mujeres, un tema novedoso para la época. Es contemporánea de Juana de Arco y escribe para ella "Canción en honor de Juana de Arco". Se la señala como precursora del feminismo occidental y primera escritora profesional de la historia.

Otros varones ilustrados que defendieron a las mujeres fueron Denis Diderot y Nicolas de Condorcet, como se señala en el libro "La ilustración olvidada: La polémica de los sexos en el siglo XVIII. Este texto recoge a varios autores, que así como argumentaban las ideas y conocimientos más modernos del momento, también sostenían la idea de la igualdad y de darles el voto a las mujeres. "Para Condorcet, una constitución no puede llamarse republicana si excluye a las mujeres del derecho de ciudadanía. El derecho natural y los principios de una república exigen la participación de todos los individuos" (Puleo, 1993).

Así también figura Poullain de la Barre (2007) quien sustentó y escribió "De la igualdad de los dos sexos" en 1,673. Aunque hay que señalar que su concepto de igualdad era universal, incluía a todos los seres humanos. Señala León (2010) sobre él, su padre lo destino a la carrera eclesiástica desde los 9 años y alcanzo el grado de maestría a los 16. Fue un sacerdote católico poco corriente, a muy temprana edad aborreció la autoridad y la intolerancia. Sus críticas lo llevaron a ser des- terrado de Paris y trabajar en lugares pobres, con el tiempo se convierte al calvinismo, lo que sumo más odio a su conducta. Un rebelde de las causas justas.

Otra mujer revolucionaria fue la francesa De Gouges (2009), quien murió en la guillotina por exigir en su manifiesto de 1789, que los derechos de ciudadanía de los hombres también lo sean para las mujeres, en su "Declaración de los derechos de la Mujer y de la ciudadanía”. Su verdadero nombre fue Marie Gouze y no solo se interesó en los derechos de las mujeres, escribió varios textos en contra de la esclavitud de los negros, el primero, una obra teatral "La esclavitud de los negros" en 1,792. A estos intelectuales se les considera parte del feminismo ilustrado.

Del siglo XVIII también es la filósofa inglesa Wollstonecraft (2005), quien se hiciera famosa por escribir "Vindicación de los derechos de las mujeres", publicado en 1792, en el que sustenta que la condición de inferioridad de las mujeres reside en un trato diferente, porque no acceden a la misma educación que los varones y que deberían ser tratadas como seres que razonan. Defendia una educación igualitaria para ambos sexos. Se la señala, como una de las pioneras del feminismo moderno.

La idea de subordinación e inferioridad de las mujeres no pudo ser desterrada con la revolución francesa, ni con el movimiento intelectual más moderno desatado en la historia de Europa y occidente. Fueron postergadas 
aunque apoyaron los ideales de: igualdad, fraternidad, libertad y la existencia de derechos universales.

El feminismo se sobrepone a la ilustración y persevera en una larga historia de malestar, opresión, disconformidad y desigualdad de las mujeres. Pero, después de todo, este movimiento intelectual legó a las mujeres un argumento que las liberaría, el principio ético-político de la igualdad. El filósofo Rousseau (2012) será el artífice de la argumentación de este concepto de la igualdad y en 1752 publicará "Discurso sobre el Origen y fundamento de la desigualdad entre los hombres" en el que señalará que la desigualdad no es parte de ningún orden natural de las cosas, ni tiene que ver con Dios. Este concepto es una construcción humana, cultural e histórica. Por lo tanto, lo que es construido a lo largo del tiempo y la historia se puede cambiar.

Rousseau (2011) fue el ideólogo de la modernidad y de la educación del siglo XVIII señalando el "cómo" de la educación de los hombres y de las mujeres en su libro "Emilio o de la Educación”. Este autor habló de cada sexo, justificando la complementariedad del hombre y la mujer. Dos naturalezas completamente diferentes, terminan en espacios de la vida diferentes. E1 espacio privado doméstico para las mujeres y el espacio político y público para los hombres. Eso justifica también recibir una enseñanza diferente.

$\mathrm{Y}$, es de este concepto de la igualdad que se apropia el feminismo, porque Rousseau no pensó en las mujeres al sustentar la igualdad entre los hombres. El afirmó, que la clase social es una estructura de poder, que sitúa a unos pocos en el poder y a la gran mayoría en condición de subordinación. El feminismo reconoce en esta misma interpretación, que el género también es una estructura de poder. No tiene que ver ni con Dios ni con el orden natural de las cosas. Lo que se entiende por conductas femeninas y masculinas corresponde a una construcción social. El género no es expresión de un destino biológico, sino más bien social. Por lo tanto, la estructura jerárquica entre hombres y mujeres también puede deshacerse.

El feminismo tiene más de tres siglos y ha convocado a múltiples investigadoras y académicas en todo el mundo y en todas las ramas del saber para analizar cómo se produce y reproduce la diferencia de poder entre un género y otro, así como para señalar soluciones y cambios.

El feminismo del siglo XIX reclamó el derecho al voto y también a la educación y contó con el apoyo interclasista de todas las mujeres, ya que ninguna podía votar, logrando unirse por intereses comunes. A mediados del siglo XX, la mayoría de países del mundo había reconocido el voto a las mujeres, con pocas excepciones.

Señala Bernàrdez (2015) que conforme las mujeres accedieron al voto $\mathrm{y}$ a la representación política, hubo un reblandecimiento del movimiento, generándose una sensación de que todo estaba ya logrado.

Estaba claro, que solo el voto, no liberaría a las mujeres de una sociedad 
que no estaba preparada para verlas de otra forma. Y la ley no es suficiente para transformar la realidad que habita en la subjetividad de cada persona y que en última instancia es la que determina nuestra actuación.

Perseverando en esta disconformidad de la experiencia de ser mujer, Simone de Beauvoir (2005) publica a mediados del siglo XX, "El segundo sexo", evidenciando que la vida de las mujeres, no era ni tan feliz ni tan igualitaria como se esperaba.

Dos décadas después, el libro de De Beauvoir, hecho raíz en nuevos feminismos, muy importantes, que implementan leyes contra la violencia de género, sobre las políticas de la igualdad entre los sexos. Se politizó lo que ocurría en los hogares, a puerta cerrada, diciendo, que allí, donde se les debería prodigar amor y cuidados a las mujeres, también encuentran violencia sexual, subordinación y hasta explotación.

Pero paralelo a estos cambios y debates positivos para las mujeres, otros malestares sociales y geopolíticos se anunciaban. El mundo asistiría a la caída de grandes ideologías, el comunismo y sobrevive a un mundo manejado por el consumo y el hedonismo (Bernárdez, 2015). Los valores sociales como la solidaridad que podían ser la columna vertebral de la unión de miles y millones de mujeres, dejaban de tener importancia. El avance de las mujeres más discriminadas del planeta, pisaría freno. Las pobres del mundo, no tendrian soporte ideológico, en un mundo que se dejaba seducir por el individualismo. La unión de las mujeres sería debilitada, por reflexiones donde el yo cobraría un sentido existencial. Las mujeres que pudieran sobrevivir como en la teoría de Darwin, al sálvense quien pueda, serian las afortunadas y con esta misma lógica estarian descalificadas aquellas que no tuvieran las condiciones superdotadas para enfrentarse a una economía de mercado o la ley de la selva. Una vez alcanzados los derechos elementales, las mujeres experimentan una división importante con la presencia del feminismo de la diferencia.

A mediados de la década del 80 se produce un choque de paradigmas, entre el feminismo de la igualdad y el de la diferencia, dando paso a la teoría Queer, otros feminismos y nuevos conceptos. En esta misma coyuntura, una mujer es elegida como primera ministra británica, Margaret Thatcher en el periodo 1979-1990, representando los intereses de las politicas conservadoras.

A estas alturas del partido, el feminismo de la diferencia no solo ha representado una posición teórica en debate, se ha producido la fragmentación del feminismo, en lo mejor de esta situación, dando libertad a muchos feminismos y en lo complicado de esta experiencia, no encontrar puntos en común, generándose silencios aun no resueltos, pendientes del balance del feminismo de la igualdad. Hay necesidad de tender puentes y ser dos brazos de un mismo cuerpo político. Y no se está hablando de un problema aislado, sucede en todos lados. 
A los feminismos actuales, les asiste problemas por resolver. Como afirma la feminista Cobo (2016) hay que poner en su sitio los debates intra feministas, enfatizando que no pueden ser su actividad central. Coloca como ejemplo la izquierda que se enloda en rupturas y debates internos y pierden de vista al capitalismo que es el mayor frente de desigualdad para las mujeres. Sostiene también que el principal objetivo político del feminismo no es la crítica a la política neoliberal sino identificar las dimensiones patriarcales del capitalismo. Pues cuando la izquierda analiza la perversidad del capitalismo nunca lo hace pensando en los efectos sobre las mujeres. Todo ello apunta a que tenemos que trabajar por puntos en común. Que el feminismo de la diferencia y la igualdad, no nos coloque en posiciones contrarias o que nos divida.

Las posturas antiesencilistas no solo del género, sino del sexo, han acabado con las mujeres en teoría. $\mathrm{Si}$ las mujeres no existen; ¿Quién defiende a las mujeres de carne y hueso que mueren todos los dias en cualquier punto del planeta? Touraine (2007) señala al respecto "si doy prioridad a la crítica radical de la noción de género es porque la convicción en la eficacia de las reformas ha retrocedido". (P. 24).

El movimiento feminista ha estado marcado por avances y en los últimos tiempos se ha detenido, sin claridad en el horizonte. Un reducido pero inteligente grupo de mujeres ha escrito una historia diferente con su propia vida, pero no ha sido suficiente para favorecer al grueso número de mujeres que todavía vive en las tinieblas de sus derechos, vulneradas hasta alcanzar la muerte en contextos de pobreza, sin acceso a la educación que les permita tomar sus decisiones y que padecen de la inercia cultural de un Estado, sociedad y justicia que conociendo la ley se resisten a cumplirla. Hay un asolapado conflicto de intereses, donde quienes teniendo el deber de protegerlas, se reconocen con el victimario o juzgan a la víctima por provocar la violencia. Esta subjetividad que está presente silenciosamente en el contexto de violencia, neutraliza los esfuerzos que se colocan en el papel, haciendo de la ley, letra muerta, logrando imponerse en la práctica, una cultura que perenniza las desigualdades de género. En esta sociedad moderna, donde muchos paradigmas sociales están en crisis, el patriarcado y el machismo sobreviven. A todos en algún momento nos toca ser víctimas, victimarios o cómplices, jueces y parte del círculo vicioso de la violencia contra la mujer.

\section{EL PERÚ GLOBAL: LA COMPLEJA REALIDAD DE LA VIOLENCIA CON- TRA LA MUJER Y EL FEMINICIDIO}

En la mayoría de los casos la violencia contra la mujer y el feminicidio están unidas a contextos de discriminación múltiple: pobreza, color de su piel, lengua propia hablada. En estos casos, concita la atención del Estado, cuando el morbo periodístico lo convierte en noticia y escándalo público. 
Muchas mujeres aceptan la violencia de género, porque no puede controlarla y ha permanecido oculta y naturalizada.

Señalan Muggah y Alvarado (2016), América Latina (AL) es una de las regiones donde más asesinatos se producen en el mundo. Los factores principales son la inequidad social y económica. Pero también mencionan qué detrás de esta excesiva violencia, están entre otros factores, las normas sociales que aprueban el machismo y la desigualdad de las relaciones de género. Por lo tanto, estas formas culturales que fomentan las jerarquías de género, no solo están detrás del feminicidio, sino también de cualquier asesinato, demostrando lo nocivo que es su presencia, convirtiéndose en una condición que fortalece la violencia.

Sobre los factores que acompañan la violencia contra la mujer, el sociólogo Touraine (2016) sostiene que la sociedad actual ha dejado de lado los lazos entre instituciones para ser un espacio de ruptura y conflicto entre el mundo de los intereses y de las ganancias y el mundo de los principios éticos. Tal situación complica la erradicación de la violencia contra la mujer, pues requiere de la presencia de instituciones públicas y privadas interconectadas y trabajando por un objetivo común. Las instituciones que deben amparar las denuncias e impartir justicia, están distantes de quienes están en la obligación proteger. Hay una conducta de incompatibilidad entre las instituciones convocadas a actuar sobre el problema y su relación con las víctimas. La mayoría de feminicidios en el Perú, más del 50\% es efectuado por una pareja o expareja y en el hogar de la víctima o de la expareja. La familia, organización fundamental de la sociedad actual, se ha convertido en un vector de violencia, donde se puede operar con impunidad.

Según el INEI (2017), las cifras de feminicidio en el Perú durante el periodo 2011-2015 sumaron 556. Durante el 2014, un estudio de 15 países en $\mathrm{AL}$, el Perú señalaba 100 víctimas y ocupaba el sexto puesto con más cifras. En la mayoría de los casos los crimenes son cometidos por la pareja o expareja; mueren acuchilladas, asfixiadas o estranguladas; y el lugar, la casa de ambos, de la víctima o victimario.

Al parecer no existe relación entre el departamento con mayor número de feminicidios y el que señala mayor porcentaje de violencia contra la mujer. Para el 2015 la mayor cifra de feminicidio se registró en el departamento de Ucayali y Tacna con 2 y 1 víctima de feminicidio por cada 100 mil mujeres respectivamente. Es preciso indicar que los departamentos de Apurímac, Lambayeque, Loreto y Tumbes no presentaron víctimas de feminicidio en dicho año (INEI, 2015).

También durante el periodo eneroset 2016, Tumbes tuvo la mayor tasa de feminicidios 3 víctimas, seguido de Tacna, 1 víctima por cada $100 \mathrm{mil}$ mujeres (INEI, 2017). Pero si observamos las estadísticas de violencia contra la mujer en el periodo 2013-2016, son Apurimac $(79,1 \%)$, Huancaveli- 
ca $(74 \%)$ y Cusco $(75,4 \%)$ los departamentos que tienen los porcentajes más altos en dicho periodo. (ENDES, 2013, 2014,2015 y 2016). A simple vista, no parece haber relación entre los departamento con estadísticas más altas de violencia contra la mujer y los que tienen las cifras de feminicidio más altas.

Tal parece, el feminicidio se produce en los departamentos sin capacidad de predecirlo. Situaciones que se pueden salirse de control en cualquier momento, sin vigilancia o control de ninguna autoridad y que germinan en cualquier parte. Nadie puede suponer que en el lugar más seguro para la mujer, encuentre la muerte en cualquier momento.

Pero tampoco se trata de un problema local, ni mucho menos propio de Perú. Según la agencia EFE (2016) la violencia contra la mujer en Francia ocasionó el deceso de 126 y 122 mujeres durante los años 2014 y 2015 respectivamente y el Perú tuvo 100 víctimas, ambos años. No se está hablando de un problema aislado. Este atraviesa el mundo en menor o mayor proporción. La tipificación de estos homicidios como feminicidios es un avance en materia de leyes, pero no, en el ámbito del cumplimiento de la justicia. Estos crímenes tienen varios culpables, entre los más visibles, el feminicida y la sociedad que fomenta con naturalidad una educación que desvaloriza a las mujeres y los roles que socialmente se les ha asignado. Las organizaciones sociales, todas y cada una que gozan de buena repu- tación, reproducen formas culturales donde las mujeres son subordinados de los hombres. La familia, la iglesia, la escuela, las relaciones sociales entre hombres y mujeres y del mismo sexo están formadas con un lenguaje y experiencias que inferiorizan la imagen femenina. Hay una gran resistencia a los cambios culturales y de mentalidad. En especial, porque esos cambios culturales, reestructuran las relaciones de poder en la sociedad.

\section{TEORÍA DE GÉNERO: LLAMADA POR SUS OPOSITORES "IDEOLO- GÍA DE GÉNERO"}

Estamos en el siglo XXI, y aún escasas mujeres entienden el intenso debate académico abierto en las universidades con la Cátedra de Género. No saben que significa el género y mucho menos han tenido el tiempo suficiente para comprenderlo. Pero, peor aún, es saber que se han opuesto, sin saber de qué se trata.

El debate en el Perú que se produce a comienzos del año 2017, aún persiste por la ejecución de un nuevo plan curricular escolar que cuestiona los estereotipos sexuales que afectan a hombres y mujeres y que propone el respeto por todas las personas por igual. Este plan tiene el propósito de evitar la violencia y bulling contra niños y niñas que no actúan bajo mandato del modelo cultural dominante, más claro, heterosexual y que en la vida cotidiana estas conductas contraculturales son rechazadas con odio y violencia. Esta violencia con la que 
actúa la mayoría expresa una normatividad impositiva, autoritaria y jerárquica.

Tal iniciativa democrática por parte del actual gobierno, ha movilizado a sectores sociales en su contra, una campaña denominada "con mis hijos no te metas", ha cautivado a familias enteras en contra del enfoque de género al cual ellos llaman "ideología de género". Bajo argumentos insostenibles como homosexualizar a sus hijos, fomentar el sexo en los niños y peor aún, considerar es, obra de "anti marías" o del demonio por sectores conservadores de la iglesia. Esta campaña se sostiene firmemente bajo el velo de miedos aprendidos, la ignorancia sobre el tema y la actitud controladora y vigilante de la iglesia sobre la familia por considerar dicha información peligrosa para sus hijos.

Lo cierto es que combatir los miedos sobre lo que muchos llaman "ideología de género" no es nada fácil. El rechazo a poner en práctica estos conocimientos, no solo anula la racionalidad de padres con precaria información sobre el tema, sino que también estos miedos sorprenden la mente de personas instruidas, que temen que esa educación confunda la orientación sexual de sus hijos. No tienen la certeza de que esa información sea inofensiva y por el contrario traiga consecuencias negativas sobre la conducta normal de sus hijos a futuro.

Pero estos miedos aprendidos tienen su propia historia que contar. Foucault (1998) señalaba en su libro Historia de la sexualidad, qué, a co- mienzos del siglo XVII se era tolerante con lo obsceno, grosero e indecente si se lo compara con los códigos del siglo XIX. Habian transgresiones visibles, anatomías que se exhibían, y que a esta desinhibida época habría seguido las noches monótonas de la burguesía victoriana. La sexualidad se había reducido a la función reproductiva en el dormitorio de los padres. Tal situación propicia la hipocresía de nuestras sociedades burguesas. Es probable que Sigmund Freud no hubiera tenido tanto éxito con el psicoanálisis si su interés no hubiera puesto el ojo en la importancia del sexo, en una sociedad cohibida de hablarlo y tildar de enfermo a cualquiera que manifieste algún malestar en relación al tema. La sexualidad recreativa era tratada como enfermedad o histeria.

La sexualidad se convierte en un tema ilegítimo y silenciado, cobrando su lugar propio en prostíbulos y manicomios. La ciencia también se vuelve cómplice de estos discursos. Por ello, es tan dificil de desmontar una cultura de la represión. El ejercicio de la sexualidad es una manifestación del control del cuerpo por el sujeto. Por lo tanto el control del propio cuerpo desestabiliza las relaciones de poder que median entre la sociedad y la iglesia.

Pero estos no son pasajes únicos en la historia de la controladora iglesia. El investigador y novelista Humberto Eco (1980), en su famosa novela "el nombre de la Rosa" describe los dramas de la época que se ambienta a fines de la Edad Media, para algunos, etapa oscurantista dónde el poder de la Iglesia 
y su control sobre el conocimiento empezaba a ponerse en cuestionamiento. La novela trata varios temas, entre ellos, varios asesinatos que ocurrían en una Abadía. Su biblioteca contaba con un libro sobre la Comedia y quien lo leyera no viviría para contarlo. Sus páginas estaban untadas con veneno. Sumo esta experiencia, para señalar que así como el sexo fue controlado y regulado por la iglesia, también lo fue la inofensiva - risa- por su poder liberador y catártico. No es extraño pensar que quien sonrie mucho, es de dudosa reputación, más si es mujer. Todas las funciones humanas que proporcionan libertad y placer han sido de especial interés por la iglesia.

Así que la idea de tocar temas centrados en la sexualidad y la libertad sexual de las personas ha estado históricamente custodiado por la iglesia. Cualquier universidad de naturaleza comercial, al ostentar un nombre religioso cuenta con mayor aceptación que si se hubiera adjudicado cualquier nombre laico. La iglesia detenta un fuerte control sobre la subjetividad de las personas y sobre sus cuerpos, normas y costumbres. El poder simbólico de las palabras, son suficientes para alcanzar credibilidad y respetabilidad sin pruebas.

En este contexto, de sexualidades reprimidas, la homosexualidad ha sido considerada por mucho tiempo una enfermedad y ha sido consistente en la creencia de las personas. Las ciencias médicas como la psiquiatría hasta antes de 1973 habian señalado a la homosexualidad como una enfer- medad psiquiátrica, considerada en el Manual Diagnóstico de Enfermedades Psiquiátricas (DSM). Otro concepto que también ha definido a estas personas es que no son normales. Sobre la genealogia del concepto normal habría que señalar que parte de su origen es estadístico, parte de un criterio cuantitativo, numérico y hace alusión al promedio aceptable. Por lo tanto, el concepto de normal, está influido por el paradigma cultural de turno. Lo normal, es lo que la mayoría hace. Y lo que la mayoría hace está sujeto a un patrón cultural social impuesto por grupos dominantes.

Volviendo a la campaña y movilización "con mis hijos no te metas" se da además en momentos en que las victimas de feminicidios ocupan la primera plana de diarios nacionales y locales. Familias enteras salen a las calles a evitar que sus hijos sean educados para respetar a hombres y mujeres por igual. Pero no marchan por motivos reales, como son los asesinatos de mujeres, que bien podría ser cualquier madre de familia. Estas familias no protestan porque sus hijas vivan libres de violencia, porque asumen que las mujeres deben vivir bajo el amparo de la familia, los hijos, el esposo o pareja. Por ellas mismas no son valoradas como sujetos que alcanzan su independencia. Las mujeres sin profesión, peor aún, no alcanzan un estatus social respetables.

Los otros factores que abonan la violencia de género, son una economía de mercado, la que tras mejorar, parece debilitar la democracia, el res- 
peto por los derechos de las personas y aún más fomenta las desigualdades entre las personas, la discriminación y la violencia estructural. El Perú crece y la educación aún sigue siendo precaria.

Esta campaña "con mis hijos no te metas" cuenta con colaboradores eficaces, como la iglesia oficial católica, unida a sectores conservadores evangélicos y apoyados por la principal fuerza política actual en el congreso. Tal situación manifiesta la distancia y el desencuentro, entre el o los debates feministas y la realidad de violencia que envuelve al sector más grueso de mujeres a nivel nacional. Las mujeres pobres saben que la violencia las acecha desde niñas. Al huir de su hogar, vuelve a la violencia, de la mano de su pareja, quien al recibir una educación machista, no puede ofrecer otro trato. Las mujeres intuyen, que no van a poder librarse de la violencia aun si conocieran sus derechos. El Estado está a miles de kilómetros de atender sus demandas al igual que su propia familia.

Una de las lecciones aprendidas de esta campaña "con mis hijos no te metas" es que se hace necesario politizar estos temas de aquí al futuro en los partidos políticos y sobretodo sensibilizar justamente a las mujeres de los sectores que entienden menos, pero que están más expuestas a la violencia de género. Sin embargo, la ausencia feminista en los partidos, es de larga data. Los aportes feministas han sido ofrecidos desde fuera de las estructuras partidarias pues, el machismo dentro, es normal. Las mujeres profesionales, que trabajan y con ideas propias, no tienen necesidad de aceptar ser relegadas a planos menores. Con esta situación, las más afectadas han sido las mujeres pobres, que participan de la militancia, sometidas al yugo masculino y que reproducen al interior los roles domésticos.

La lucha por el poder en los partidos políticos ha subordinado el debate interno del género a planos inexistentes, como si esos problemas no atravesaran la organización política. El debate sobre el poder, se sobreentiende que pertenece solo a la agenda masculina. Las dirigentes mujeres ya tienen su lugar, ocupándose de las organizaciones de mujeres, sean los Club de Madres (APRA), Vaso de leche (IU), Comedores Populares (AP), cada gobierno y partido político ha bautizado una de estas organizaciones, que se fundamentan sobre la división social y sexual del trabajo y donde los hombres están ausentes. También estas organizaciones cuentan con una secretaría de mujeres, las que atienden asuntosvalga la redundancia- "femeninos". No existe una sola organización social que esté libre de esta división social y sexual del trabajo.

La participación política en tiempos de decadencia de los partidos y de los hombres en la politica, le han permitido a las mujeres oxigenar, renovar viejos y desgastados rostros en la lucha por el poder. No es que se lo han ganado ellas en la lucha por el poder político. Es parte de una iniciativa legal por democratizar la participación 
de las mujeres en la política. Sin embargo, esta participación política no se legitima, porque desde dentro de la propia organización política estos temas no son considerados importantes dentro de la agenda partidaria. Por otro lado, las políticas públicas reproducen modelos de participación femenina que reproducen un rol tradicional de las mujeres. De esta manera, esta situación se vuelve de fácil manejo para los hombres, donde las mujeres son vistas como un aliado fácil y manipulable. Además, acorde con los tiempos actuales, es casi un mandato mundial, que ellas sean incluidas en las listas de procesos electorales, bajo diversos mecanismos. En el Perú en el año 1997 se modificó la legislación electoral para introducir la cuota de género, con el fin de que se garantice el derecho de las mujeres a ser elegidas en igualdad de condiciones que los hombres. (ONPE, 1997).

De esta forma, las organizaciones políticas cumplen con la formalidad, de incluirlas en sus listas electorales, pero esperando no salgan elegidas, ya que al interior de la organización son poco promovidas o si salieran elegidas, esperan que sean dóciles al mandato masculino. Juega a favor también, que todavía son muy pocas las que se interesan en la lucha por el poder político como un espacio de desarrollo.

En relación a otra dimensión de la vida de las mujeres, sus inquietudes profesionales, están todavia muy marcadas por los espacios que siempre se han dominado. Señala Touraine (2016) "se habla de igualdad de acceso a todas las profesiones, pero la mayoría de las mujeres ejercen las profesiones menos remuneradas, en el campo social o cultural, la enseñanza, los cuidados médicos o la justicia, en todo lo que "no produce dinero "y de que se mofan los que pertenecen al 1\%superior en la jerarquía de los ingresos" (p. 190). Y Enfatiza que es en el plano privado y en la experiencia de la violencia donde las mujeres experimentan la mayor vulneración de sus derechos.

En razón de los temas expuestos, se sugiere que los feminismos están llamados a manifestarse bajo el impulso de una fuerza política. Aunque el primer problema a esta afirmación será la débil aceptación de los partidos en el presente y aún más dificil es pensar en una izquierda que represente estos intereses. Sendero luminoso ha empedrado el camino de la izquierda politica por un buen tiempo y es necesario además un discurso más moderno. La derecha, experimenta menos problemas, porque las mujeres que tienen dinero, pueden exigir que la ley se cumpla o pueden educar a sus hijas en colegios privados donde serán respetadas por su dinero o porque al pertenecer a una clase media profesional, estos discursos forman una barrera para confrontar la violencia. En la economía de mercado en que vivimos las mujeres se pueden blanquear con dinero y ser más respetables por ese mismo motivo.

La teoría de género, aunque no es un debate que nace en los claustros universitarios del Perú, hoy se desarrolla en varias universidades de res- 
petable reputación académica dentro y fuera del país, con casi dos décadas en la implementación de diplomados y maestrias en estudios de género. E1 frente teórico del feminismo se abre paso con otros grupos minoritarios denominados LGBT.

La violencia de género, todavía es el hilo conductor que une sociedades modernas y no modernas. Se experimenta en el país de la ilustración cultural y del siglo de las luces, como en el Perú. Las complejas disquisiciones teóricas del feminismo, son parecidas en todas partes.

Hay varios feminismos y se necesita uno que se encargue de desmontar la violencia de género en especial de las mujeres pobres. La ley, la cárcel, la cadena perpetua o el suicidio del feminicida, no curan la enfermedad social. El saldo de mujeres asesinadas, de padres que cumplen pena de cárcel por feminicidio, convierten el mal, en una enfermedad crónica. La justicia en estos casos no es suficiente con pagar la pena, no tiene que ver con la ley, tiene que ver con la posibilidad de que la muerte de estas mujeres, no cobre más víctimas en el futuro. No se trata de males germinados en la mente malvada y aislada de alguien, se trata de males que germinan en cualquier parte y en mujeres y hombres por igual. El feminicidio, bajo el modelo de convivencia patriarcal-machista, germina violencia todos los días. Se forman hijas, para tolerar la violencia y se forma hijos para usar la violencia como mecanismo de control. El feminicidio es la etapa final de una pirámide de ancha base que tiene a sus pies, las potenciales víctimas. Llegar a la cima de la violencia depende del deseo de libertad que libre cada mujer por recuperar su destino, el que ella elija y es cosa de suerte salir viva o muerta en ese intento.

Mientras la violencia simbólica patriarcal flote en la mente de hombres y mujeres por que no se ha destruido el patrón cultural que la sostiene, la violencia de género seguirá manifestándose en un desenlace fatal e incontrolable en cualquier momento. Se trata de una enfermedad mental, provocada por un modelo cultural. Según Foucault (2009), la psicología occidental es como cualquier otra forma de cultura, organiza un saber, se institucionaliza, desarrolla un lenguaje propio y alcanza una forma científica. De ser así, lo que consideramos normal, no es más que un patrón cultural construido. El machismo es un sistema cultural construido y que ha naturalizado la jerarquía y superioridad del hombre sobre la mujer. La transgresión a este orden cultural es lo que provoca la violencia de género. Descargar el machismo impregnado en el discurso cotidiano, es repensar casi todas las normas, incluso las más inofensivas cargadas de amor filial.

\section{POR ENCIMA DEL DEBATE FEMI- NISTA INTERNO, LAS ALIANZA SON NECESARIAS}

El movimiento feminista que dio origen a la protesta social y a la visibilidad de las mujeres y que alcanzó 
un carácter universal y global, hoy expresa como todos los movimientos sociales debilidad y ausencia. Las mujeres están divididas entre intelectuales teóricas que debaten sobre el género, las victimas de feminicidio y las que marchan para que se acabe la violencia contra la mujer. Desconectadas, fragmentadas e hipnotizadas, por una perversa lógica individualista y hedonista de estos tiempos. El feminismo está disperso y en crisis de paradigmas. Se está como los partidos políticos, feminismo sin militancia. Hoy también en crisis global.

Se ha dejado de creer qué el 50\% de mujeres perseguía las mismas libertades y derechos que los hombres. Ya no somos la mitad de la población que quiere vivir en iguales condiciones que los hombres. La mirada sobre la situación de las mujeres ha cambiado.

La unidad ya no existe. Las construcciones y categorias de género, son parte del debate académico actual y también parte de la división. El reconocimiento de las minorías sexuales y comprendidas dentro de estas minorias las mujeres no heterosexuales, son precisamente estos grupos los que lideran el movimiento feminista, por una razón entendible, la búsqueda del reconocimiento de sus derechos en la sociedad. Estos grupos además cuentan con una militancia más activa. Estamos presenciando el agotamiento del feminismo de la heterosexualidad y de la igualdad. No se está planteando el desconocimiento de los feminismos de la diferencia u otros, se está planteando la defensa de un feminismo que haga alianzas con otros feminismos.

Mientras este panorama no tenga más claridad y esté ausente de un carácter vinculante entre la teoría de género, la violencia contra la mujer y el activismo político en las calles, las cifras de feminicidio serán evidencia de cada día. Las marchas de NI UNA MENOS tendrán el eco del día y de la fecha, las redes sociales podrán saturarse de mensajes en contra de la violencia, pero no podrán detenerlo. El cambio real, no es virtual. Se requiere de trabajo y de tiempo real para transformar la sociedad. La violencia contra la mujer es el síntoma de una enfermedad que nos anuncia que el patriarcado y el machismo gozan de buena salud todavia. Hay feminismo para rato, hasta que las mujeres alcancen a vivir libres de violencia, de una vez y para siempre. 


\section{REFERENCIAS BIBLIOGRÁFICAS}

Agencia EFE. Cada tres días muere una mujer en Francia a causa de violencia machista. 23 de noviembre de 2016, Fecha de acceso 12 de julio de 2017. http://www.elcomercio.com/tendencias/asesinatos-mujeres-francia-violenciadegenero-femicidios.html

Bernárdez, A. (2015). (Mujeres en Medio(s): Propuesta para analizar la comunicación masiva con perspectiva de género. España: Editorial Fundamentos.

Cobo, R. (29 de enero 2013). Nuevas formas de violencia contra las mujeres. Organiza Instituto Estatal de las Mujeres de Nuevo León, México. Evento conmemorativo del Día Internacional de la no violencia contra las mujeres. Casona Santa Lucia, realizado el 28 de noviembre de 2012. Recuperado de https:// www.youtube.com/watch?v=eVUXnHnSOpA

Cobo, R. (9 de Noviembre 2016). Conferencia Las Olas del Feminismo. Universidad de Vigo. Recuperado: https://tv.uvigo.es/video/130456.html

De Gouges, O. Declaración de los derechos de la mujer y de la ciudadana Olympe de Gouges, 1789. Revista Historia de la Educación Latinoamericana, vol. 13, 2009, pp. 267-279. ISSN: 0122-7238. Universidad Pedagógica y Tecnológica de Colombia. Boyacá, Colombia. Recuperado en http:/ / www.redalyc.org/ articulo.oa?id=86912384014

De Pizan, C. (2001). La ciudad de las damas. España: Ediciones Siruela. Recuperado de https://seminariolecturasfeministas.files.wordpress.com/2012/01/ la-ciudad-de-las-damas-texto.pdf

Eco, U. (1980). El nombre de la rosa. Argentina: Editorial Lumen.

ENDES. (2014). Perú. Encuesta demográfica y de salud familiar 2013. Nacional y Departamental. Capítulo 12. Violencia contra las mujeres, niñas y niños. INEI.

http:/ /www.inei.gob.pe/media/MenuRecursivo/publicaciones_digitales / Est/Lib1151/index.html

ENDES. (2015). Perú. Encuesta demográfica y de salud familiar 2014 Nacional y Departamental. Capítulo 12. Violencia contra las mujeres, niñas y niños. INEI. http://www.inei.gob.pe/media/MenuRecursivo/publicaciones_digitales / Est/Lib1211/index.html

ENDES. (2016). Perú. Encuesta demográfica y de salud familiar 2015. Nacional y Departamental. Capítulo 12. Violencia contra las mujeres, niñas y niños. INEI. https://www.inei.gob.pe/media/MenuRecursivo/publicaciones_digitales/Est/Lib1356/index.html

ENDES. (2017). Perú. Encuesta demográfica y de salud familiar 2016. Nacional y Departamental. Capítulo 12. Violencia contra las mujeres, niñas y niños. INEI. https://www.inei.gob.pe/media/MenuRecursivo/publicaciones_digitales/Est/Lib1433/index.html 
Foucault, M. (1998).Historia de la sexualidad I. La Voluntad del saber. México: Siglo XXI. Recuperado en HTTP://BIBLIOTECA.D2G.COM http://www. uruguaypiensa.org.uy/imgnoticias/681.pdf

Foucault, M. (2009). Filosofia y psicología. Entrevista por Alain Badiou. https: / / www.youtube.com/watch?v=1e8Rynio0B8

Instituto Nacional de Estadística e Informática. (2017). Perú: Estadísticas de Feminicidio. Registros Administrativos. Sintesis Estadística. Lima: INEI. Recuperado en http://www.inei.gob.pe/media/MenuRecursivo/boletines/boletin_feminicidio.pdf

INEI. (2015). Capitulo III- Calificación Preliminar de Feminicidio 2015.INEI. Recuperado en https://www.inei.gob.pe/media/MenuRecursivo/publicaciones_digitales/Est/Lib1365/cap03.pdf

Leon, E. (2010). François Poulain de la Barre: Feminismo y Modernidad. Astrolabio. Revista internacional de filosofia. Año 2010 Núm. 11. ISSN 16997549. pp. 257-270. http://www.raco.cat/index.php/Astrolabio/article/viewFile/239029/321290

Muggah, R, Alvarado, N. (Viernes 30 de setiembre de 2016). Homicidios en América Latina: seamos ambiciosos. El País Internacional. Sección opinión, Pag. 12 .

Oficina Nacional de Procesos Electorales (ONPE).LEY N. ${ }^{2}$ 26859. Ley Organiza de elecciones. (En línea). Perú. 1 de octubre de 1997. Fecha de acceso 16 de julio de 2017. URL disponible en: https://www.web.onpe.gob.pe/modCompendio/html/ley_organica_menu.html.

Poullain de la Barre, F. (2007). La igualdad de los sexos. Discurso físico y moral en el que se destaca la importancia de deshacerse de los prejuicios. México. Centro de Investigaciones Interdisciplinarias en Ciencias y Humanidades. Universidad Nacional Autónoma de México.

Puleo, A. (1993). La ilustración olvidada: La polémica de los sexos en el siglo XVIII / Condorcet, de Gouges, De Lambert y otros. España. Editorial Anthropos. Recuperado de http://www.reduii.org/cii/sites/default/files/field/doc/La\%20 ilustracion\%20olvidada-polemica\%20sexosXVIII.pdf

Rousseau, J-J. (2011). Emilio o de la Educación. España. Alianza Editorial.

Rousseau, J-J. (2012). Discurso sobre el origen y los fundamentos de las desigualdades entre los hombres. México. Cien del Mundo.

Touraine, A. (2007). El mundo de las mujeres. España: Editorial Paidós.

Touraine, A. (2016). El fin de las sociedades. México: Editorial Fondo de Cultura económica.

Wollstonecraft, M. (2005).Vindicación de los derechos de la mujer. Edición de Marta Lois González. Colección Fundamentos n. 225.Serie Clásicos del pensamiento político. España. Ediciones Istmo. Recuperado en http://www.akal. com/libros/VindicaciOn-de-los-derechos-de-la-mujer/9788470904646\# 